\title{
Subacute Granulomatous Thyroiditis
}

National Cancer Institute

\section{Source}

National Cancer Institute. Subacute Granulomatous Thyroiditis. NCI Thesaurus. Code C35828.

Self-limited inflammation of the thyroid gland characterized by the presence of multinucleated giant cells. Patients present with neck pain, often associated with fever and dysphagia. The clinical course includes an initial phase of hyperthyroidism, followed by a phase of hypothyroidism, and eventually a return to normal thyroid function. 